\title{
关于智慧养老服务需求影响因素的思考
}

\author{
许家雄 傅陶莎 李炳辉
}

江西经济管理千部学院

DOI:10.32629/er.v2i10.2067

[摘 要] 当前,我国老龄化趋势日益明显,养老也成为社会关注的焦点。日渐兴起的智慧养老模式能够有效解决社会发展中产生的养老问题。 本文主要分析了智慧养老服务需求的影响因素以及发挥智慧养老的主要措施。

[关键词] 智慧养老; 服务需求; 影响因素; 主要措施

当前, 我国面临着十分严峻的老龄化趋势, 人们观念的变化改变了家 庭结构, 子女的养老负担明显加重。随着高科技的飞速发展, 养老服务出现 了智慧养老模式。智慧养老模式能够利用多种先进的科学技术提供更加全 面的养老服务。且我国也鼓励出台了多种政策发展智慧养老服务, 建立更 为完善的养老服务体系, 以期更好地解决社会养老问题。

\section{1 智慧养老概述}

智慧养老主要是针对居家老人、社区养老机构的传感网系统与信息平 台, 同时以此为基础提供更加完善和细致的智慧化养老服务 ${ }^{[1]}$ 。我国科学 技术不断完善, 全新的养老方式也成为了流行趋势, 电视盒子等多种科技 产品明显增多, 这提高了老年人的生活质量, 避免空巢老人的寂寞。现阶段, 我国养老逐渐朝着候鸟式养老和信息化养老发展, 智慧养老获得了社会各 界的认可, 互联网为很多老年人打造了更加舒适和方便的生活。

\section{2 智慧养老服务需求的影响因素}

2. 1智慧养老顶层设计不合理, 缺乏统一标准规范

由于我国智慧养老项目起步发展时间较晚, 绝大多数城市的智慧养老 项目仍处于初级发展阶段, 尚未形成系统化、规模化与标准化。尽管从社 会性质层面来说, 智慧养老项目是由各基层政府部门主导的, 但事实上, 各 城市的智慧养老项目的管理工作仍以独立治理为主 ${ }^{[2]}$ 。这种独立治理模式, 使得自然资源、人力资源与技术资源闲置, 综合利用率偏低, 而且存在主资 源重复利用, 资源过度闲置的问题。归根究底, 出现这些问题的主要原因就 是顶层设计不合理, 整体规划不完善, 且智慧养老项目的管理工作也存在 诸多不足。

另外, 目前国内关于智慧养老服务的法律条例尚未完善, 而且现有的 法律条例内容空泛, 偏重于宏观性指导, 缺少建设性意见, 无法为智慧养老 项目的运转提供必要的法律保障。

\section{2 智慧养老服务人员匮乏}

基于国内智慧养老项目的经营发展水平偏低, 智慧养老服务团队尚未 完善化, 专业服务人员贵乏。同时, 智慧养老产品的研发投入力度偏低, 主 流产品与附属产品数量有限, 无法满足所有老年人的基本需求。而智慧养 老产品使用率低也是制约行业良好发展的主导因素。
智慧养老是以互联网技术、物联网技术、大数据技术与云计算技术为 核心的养老服务体系。无论是智慧养老产品研发, 还是完善智慧养老主流 产品与附属产品性能, 都需要依赖于高素质的全面型技能人才。由此可见, 保障人才储备是促进智慧养老产业发展的必要条件。

另外, 智慧养老服务团队应当与老年群体保持良好的沟通, 全面了解 老年群体对智慧养老项目的需求。客观的说, 由于老年人视觉、听觉不灵 敏, 且语言表达能力有限, 所以就加大了沟通交流的难度。而这也对智慧养 老服务人员的综合素质提出了更高的要求。

2.3 智慧养老产品普及率较低, 宣传推广不到位

冊庸置疑, 智慧养老产品的服务对象是老年群体, 而老年人思想保守, 往往更倾向于循规蹈矩的生活模式, 要求其完全接受新的事物需要一定的 时间。通过专项调查可知, 部分老年人认为智慧养老产品的使用流程繁琐 复杂; 部分老年人认为互联网的开放性与共享性会使个人隐私遭到泄露; 部分老年人思想前卫, 表示能够接受智慧养老产品, 但出于生活节俭, 过度 注重产品价格; 部分老年人习惯于以往的生活习惯, 完全不接受智慧养老 产品, 认为是多此一举 ${ }^{[3]}$ 。

老年群体的这些思想负担, 很大程度的降低了智慧养老产品的普及 率。结合实际调查可知, 了解智慧养老服务项目的老年人仅占整个老年群 体的一小部分, 大多数老年人对智慧养老闻所未闻, 更谈不上接受。这也充 分体现出各基层政府对于智慧养老服务项目的宣传推广落实不到位。

2.4智慧养老服务信息系统安全性缺乏保障

个人隐私与使用安全是老年人较为关心的两个问题。个人隐私具体包 括个人身份信息与生活方式。个人信息的泄露, 极易给老年人带来电话骚 扰与上门营销等困扰, 进而影响老年人的正常生活。再者, 采集数据信息, 也使得对生活私密程度较高的老年人倍感压力, 这进一步削弱了其对智慧 养老服务的积极性。

基于我国智慧养老项目尚处于初级发展阶段, 专业技术不成熟、不完 善, 所以也为不法分子入侵监测系统提供了可乘之机, 一方面, 对老年人的 个人信息安全构成潜在威胁, 另一方面, 影响了老年群体对智慧养老服务 的评价, 削弱群众基础。
方式, 努力把学生培养成新时代所需要的生态人, 从而为实现美丽中国建 设的中国梦蓄力㖨砖。

\section{[参考文献]}

[1]胡金木.生态文明教育的价值愿景及目标建构 [J].中国教育学 刊,2019(04):34-38.

[2] 习近平.决胜全面建成小康社会夺取新时代中国特色社会主义伟大胜利 一在中国共产党第十九次全国代表大会上的报告[N].人民日报,2017-10-28.

[3]《十九大报告辅导读本》编写组所编著. 党的十九大报告辅导读本
[M].北京: 人民出版社,2017(10):49.

[4]李娟.新时代中国共产党生态文明教育的基本方略与特点 [J].思想 理论教育导刊,2019(04):66-69.

[5]枈克. 担起生态文明教育的历史责任培养建设美丽中国的一代新 人[J].中国高教研究,2018(08):1-5.

\section{作者简介:}

孟春红, (1992--), 女, 汉族, 河南幞阳人, 硕士, 单位: 河南大学马克 思主义学院学科教学(思政)专业, 研究方向: 生态文明教育。 


\section{3 促进智慧养老产业良好发展的可行性策略}

3. 1 进一步明确政府职能

首先, 各基层政府部门应统一智慧养老产品研发标准与服务标准。其 一, 各基层政府应制定系统性、合理性与可行性的智慧养老服务标准规范、 质量监控标准规范、风险预防标准规范与绩效评估标准规范。针对智慧养 老服务人员, 严格执行 “持证上岗” 原则, 保证服务效率; 其二, 构建完善 的智慧养老服务项目扶持制度, 逐步细化扶持制度, 如产品研发、产品认 证、产品营销、产品更新等 ${ }^{[4]}$ 。基于智慧养老服务项目优惠政策, 进一步 明确不同老年群体的补贴标准, 做到项目综合效益的最大化。

其次, 创建完善的智慧养老网络信息系统。各基层政府部门应注重部 门协调与社会治理, 从单一的社区数据整合过渡到街道、辖区与市区的数 据整合, 建立系统化、完整化与动态化的老年群体数据库, 实现养老信息平 台的高层级化建设与跨区域化建设, 促进资源共享。同时加强信息系统监 管, 保护老年人隐私, 从根本上解除老年人的信息安全担忧, 提升智慧养老 项目的综合服务水平。

最后, 加大智慧养老产品与服务的宣传投入力度。采取老年群体容易 接受的方式进行宣传。例如, 张贴海报、派发宣传单、滚动电子屏、登电 视广告等。且提供免费体验活动, 引导老年人客观认知智慧养老产品与服 务。再者, 要注重智慧养老产品与服务的优惠政策的宣传工作, 增强社会公 众对宏观政策的认同感与信任感。

3. 2加大智慧养老产品研发力度, 完善综合服务品质

根据全国第四次城乡老年人生活状况普查结果可知, 供需关系失衡问 题尤为突出。对此, 各基层政府部门要保证智慧养老产品与服务的多元化, 提升产品普及率与服务水平。一方面, 要加大智能产品研发与推广力度, 另一方面, 注重智慧养老服务的多元化与精准化。按照智慧养老产品的配 置规格差异, 可划分为设备类硬件和医疗类硬件两类。设备类硬件主要包 括监护提醒、健康监测、生活辅助类与娱乐设备等; 医疗类硬件主要包括 轮椅、护理床与外骨骼等 ${ }^{[5]}$ 。

在此方面, 我们可以经济借鉴丹麦的居家护理服务模式, 依靠智能语 音门、清洁机器人与电动调节床, 保障老年群体生活的便捷性与安全性。 根据老年人实际需求, 增加上门医疗服务、清洁服务与康复护理服务与心 理咨询服务, 以满足老年人的多元化需求。

便利性是影响老年人对智慧养老产品与服务评价水平的关键指标。为 此, 要注重产品与服务流程的简便化。智能设备供应商应注重技术创新, 简化设备操作流程, 从而降低操作难度系数, 加强使用的时效性与安全性。 且不断完善基础设施与娱乐设施配置, 如血氧仪、药箱与智能下棋等。
3. 3加强智慧养老服务团队建设

一方面, 全面推广家庭医生签约工作。家庭医生是智慧养老的服务主 体。为此, 应当加速推进老年人家庭医生签约工作, 不断扩大家庭医生签约 服务覆盖率。家庭医生可以通过养老信息平台完成签约老人的在线咨询, 实时关注服务对象的身体健康状况, 为其提供专业的医疗服务、康复护理 服务与保健服务。另一方面, 针对医疗护理人员匮乏、家政服务歧视等问 题, 要制定并出台养老服务人员薪资补贴政策, 完善薪资待遇, 扩大养老服 务队伍。同时, 积极开展智慧养老服务人员培训班, 设置基础护理、紧急救 护、家政服务与心理服务等多元化课程, 不断完善服务人员的专业技能, 强化其职业道德素养。

3. 4 注重智慧养老服务信息系统安全防护

各基层政府部门不仅要加大智慧养老产品与服务宣传推广工作投入 力度, 还需注重信息系统安全防护工作, 维护参与智慧养老服务项目的老 年群体的个人隐私。政府部门应当在社区开设智慧养老服务培训课程, 让 老年人全面了解智慧养老服务体系, 增强网络计骗防范意识。

\section{4 结束语}

综上所述, 当前我国已进入老龄化社会, 且老龄化趋势不断加重。由此, 养老问题也成为社会各界关注的焦点。基于互联网的普及与信息技术的拓 展应用, 全面推广智慧养老项目具有实际意义。为保障智慧养老项目的实 际效能, 各基层政府部门应加大对智慧养老产品研发力度, 优化智慧养老 服务水平, 以满足老年群体的基本生活需求。

\section{[参考文献]}

[1]黄伟,袁竞峰,李灵芝.基于个体需求的智慧养老服务体系构建与平 台设计[J].工程管理学报,2018,32(03):147-152.

[2]李大伟.基于主动服务的智慧养老服务模式[J].承德石油高等专科 学校学报,2018,20(03):92-94.

[3]李彩宁.构建智慧养老服务体系及平台[N].中国人口报,2019-02-22(003).

[4]王亚风.我国政府购买公共服务的模式研究[D].郑州大学,2012,(10):61.

[5]王欣刚.信息化养老服务系统平台的规划与设计[D].南京邮电大 学,2012,(07):40.

\section{基金项目:}

2019年江西省高校人文社会科学研究一般项目(项目名称：江西 省养老社会化服务体系建设研究); 江西经济管理千部学院2019年度 院级科研项目 (项目名称: 《江西社会化养老服务体系建设研究》, 项目 编号：2019RKXYB005))。 